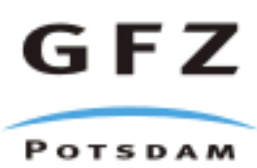

Originally published as:

Lombard, A., Garcia, D., Ramillien, G., Cazenave, A., Biancale, R., Lemoine, J. M., Flechtner, F., Schmidt, R., Ishii, M. (2007): Estimation of steric sea level variations from combined GRACE and Jason-1 data. - Earth and Planetary Science Letters, 254, 1-2, 194-202,

DOI: 10.1016/j.epsl.2006.11.035. 


\title{
Estimation of steric sea level variations from combined GRACE and Jason-1 data.
}

\author{
A. Lombard ${ }^{1}$, D. Garcia ${ }^{2}$, G. Ramillien ${ }^{1}$, A. Cazenave $^{1}$, R. Biancale ${ }^{3}$, J.M. \\ Lemoine $^{3}$, F. Flechtner ${ }^{4}$, R.Schmidt ${ }^{4}$ and M. Ishii ${ }^{5}$.
}

1. LEGOS-CNES, Observatoire Midi-Pyrénées, Toulouse, France

2. Space Geodesy Laboratory, Applied Mathematics Department, EPS, University of Alicante, Spain

3. Groupe de Géodésie Spatiale, CNES, Toulouse, France

4. GeoForschungsZentrum Potsdam, Potsdam, Germany

5. Frontier Research Center for Global Change, Japan Agency for Marine-Earth Science and Technology, Yokohama, Japan

Corresponding author:

A.Lombard, LEGOS-CNES, OMP, 18 Avenue E. Belin, 31401 Toulouse cedex 9

Tel: (+33) 05613330 52, Fax: (+33) 05612532 05,

Email: Alix.Lombard@,notos.cst.cnes.fr 


\section{Abstract}

We estimate the mean steric sea level variations over the $60^{\circ} \mathrm{S}-60^{\circ} \mathrm{N}$ oceanic domain for the recent period (from August 2002 to April 2006), by combining sea level data from Jason-1 altimetry with time-variable gravity data from GRACE. The observed global mean sea level change from satellite altimetry results in total from steric plus ocean mass change. As GRACE measurements averaged over the ocean represents the ocean mass change component only, difference between GRACE and altimetry observations provides an estimate of the mean steric sea level. Two different sets of GRACE geoid solutions (the GRGS EIGENGL04 and the GFZ EIGEN-GRACE04S products) have been used. Each GRACE data set ranges over approximately three years or more (August 2002 -April 2006 for the GRGS geoids and February 2003 - February 2006 for the GFZ geoids).

We first focus on the seasonal variations. The two GRACE data sets agree very well in terms of mean annual mass variation, both in amplitude (approximately $7.3 \mathrm{~mm}$ equivalent sea level) and phase (maximum on October 14). For both time spans, Jason-1 sea level minus GRACE ocean mass has an annual amplitude of approximately $5.8 \mathrm{~mm}$ with a maximum on March 11. The latter signal compares well with the steric annual sea level estimated from the World Ocean 2004 climatology and the Ishii et al. (2006) ocean temperature data. We also examine the interannual fluctuations of the Jason-1 minus GRACE sea level. The two resulting steric sea level time series (based on the two GRACE data sets) agree well. The inferred steric sea level curve exhibits an increasing trend during the last 3.5 years (August 2002- April 2006), of the same order of magnitude as the 1993-2003 steric sea level trend computed with in situ hydrographic data. However over the last 3.5 years, we note a strong discrepancy between altimetry minus GRACE and in situ-based steric sea level trend, the latter exhibiting a negative slope. The cause for such a discrepancy is yet unknown but may be related to inadequate sampling of in situ ocean temperature measurements 


\section{Introduction.}

In March 2002, a new generation of gravity missions was launched: the Gravity Recovery and Climate Experiment (GRACE) space mission [1,2]. GRACE now provides an invaluable set of new observations allowing us to quantify the spatio-temporal change of total terrestrial water storage (underground and surface waters, snow and ice mass changes). In addition the GRACE data over the oceanic domain can provide information on ocean mass change (one of the two contributions to sea-level change, i.e., that resulting from water mass addition due to land ice melt and exchange with terrestrial storage).

GRACE measures spatio-temporal variations of the gravity field with an unprecedented resolution and precision, over time scales ranging from about 10 days to several years. These spatio-temporal gravity variations can be expressed in terms of lateral mass redistributions assuming they are caused by surface water changes inside the surface fluid envelopes of the Earth (oceans, atmosphere, ice caps, and continental reservoirs). GRACE quantifies vertically-integrated water mass changes with a precision of a few $\mathrm{cm}$ in terms of water height for a spatial resolution of approximately $500 \mathrm{~km}$ (e.g., [3-10]). GRACE measurements have already been used to determine mass balance of the ice sheets and corresponding contribution to sea level [11-14], ocean mass change [15] and geographically averaged thermal expansion when combined with satellite altimetry $[16,17]$. In the present paper we focus on the latter application.

\section{GRACE Data}

The data set provided by the GRACE project consists of monthly sets of spherical harmonic geoid coefficients (and associated uncertainties) up to degree and order 100 to 120 for the time span starting in April 2002 or a few months later depending on the GRACE data processing center and data release. These coefficients are derived from raw tracking measurements (GRACE consists of a pair of satellites whose mutual distance, absolute positions and velocities are continuously monitored), they are computed by the Center for Space Research (CSR) and Jet Propulsion Laboratory (JPL) in the USA, and the GeoForschungsZentrum (GFZ) in Germany. Recently another group has computed GRACE geoid solutions (GRGS, France).

The static component of the gravity field is mainly due to solid Earth contributions and it explains nearly 99 per cent of the total gravity field. The time-variable component generally is 
expressed as geoid anomalies with respect to the static field, and the latter is approximated by the temporal mean of a several-year time series of GRACE geoids.

The time dependent spherical harmonic geoid coefficients, $\left\{\delta C_{n m}(t)\right.$ and $\left.\delta S_{n m}(t)\right\}$, where $n$ and $m$ are the degree and order respectively, define the time-variable geoid anomalies:

$$
\delta G(t)=\sum_{n=1}^{N} \sum_{m=0}^{n}\left(\delta C_{n m}(t) \cos (m \lambda)+\delta S_{n m}(t) \sin (m \lambda)\right) P_{n m}(\cos \theta)
$$

Herein (1) $N$ is the maximum degree of the decomposition, $t$ is time, $\theta$ is the co-latitude, $\lambda$ is the longitude and $P_{n m}$ is the associated fully normalized Legendre polynomial. Degree $N$ is equivalent to a spatial wavelength $\lambda$, where $\lambda$ is approximately $2 \pi R_{e} / N\left(R_{e}\right.$ is the mean Earth's radius $\sim 6371 \mathrm{~km}$ ). The time variable geoid is classically expressed as a surface load function $\delta q(\theta, \lambda, t)$ related to the geoid spherical harmonics by (e.g., [18]):

$$
\left(\begin{array}{l}
\delta C_{n m}(t) \\
\delta S_{n m}(t)
\end{array}\right)=\frac{\left(1+k_{n}^{\prime}\right) R_{e}^{2}}{(2 n+1) M} \iint_{S} \delta q(\theta, \lambda, t)\left(\begin{array}{c}
\cos \\
\sin
\end{array}\right)(m \lambda) P_{n m}(\cos \theta) \delta S
$$

where $k_{n}$ represents the load Love numbers that allows taking into account the elastic compensation of the Earth to surface load and $M$ is the Earth's mass. Because of orthogonality of Legendre polynomials, the spherical harmonic coefficients of the GRACE geoids are linearly related, for a given degree and order, to corresponding spherical harmonic coefficients of the load function $q$, so that it is easy to deduce the surface load from (2). The load can be further simply expressed in terms of equivalent water height, either globally or regionally.

Water volume variation due to water mass change of the ocean over the $60^{\circ} \mathrm{S}-60^{\circ} \mathrm{N}$ area $\delta \Psi(t)$ is computed using the scalar product relation:

$$
\delta \Psi(t)=4 \pi R_{e}^{2} \sum_{n=1}^{N} \sum_{m=0}^{n}\left\{A_{n m} \delta C_{n m}(t)+B_{n m} \delta S_{n m}(t)\right\}
$$

where $A_{n m}$ and $B_{n m}$ are normalized harmonic coefficients of the geographical mask used to mark the boundary of the studied area. We construct this geographical mask over the $60^{\circ} \mathrm{S}$ $60^{\circ} \mathrm{N}$ ocean domain using a $400 \mathrm{~km}$ Gaussian filter [19]. 
The corresponding global mean sea level (water mass component) is computed by dividing estimated water volume variation $\delta \Psi(t)$ by the $60^{\circ} \mathrm{S}-60^{\circ} \mathrm{N}$ ocean surface $(\sim 325$ millions of $\mathrm{km}^{2}$ ) at each time step. As we are interested in temporal variations of the global mean sea level, the time-averaged mean value over the whole period is removed from each individual solution.

Errors associated to each spherical harmonics coefficient are provided with the geoid solutions. The error on the water volume change estimate is computed from the errors on the equivalent water height coefficients $\sigma(t)=\left(\delta \sigma_{n m}^{C}(t), \quad \delta \sigma_{n m}^{S}(t)\right)$ (themselves based on the errors attached to the geoid coefficients through (1) :

$$
\sigma(\delta \Psi(t))=4 \pi R_{e}^{2} \sqrt{\sum_{n=1}^{N} \sum_{m=0}^{n}\left\{\left(A_{n m} \delta \sigma_{n m}^{C}(t)\right)^{2}+\left(B_{n m} \delta \sigma_{n m}^{S}(t)\right)^{2}\right\}}
$$

\section{GRGS GRACE gravity field solutions}

In this study, we use the 128 global solutions of the Earth gravity field (i.e. the geoid) recently computed by Biancale et al. [20], called GRGS-EIGEN-GL04 fields. These solutions consist of spherical harmonic coefficients, from degree 2 up to degree and order 50 (corresponding to a spatial resolution of $400 \mathrm{~km}$ at the surface of the Earth) at 10-day intervals for August 2002 through April 2006 (however 9 solutions are missing). It is worth to note that degrees 51 to 150 were solved for in a static manner based on all available 10-day intervals. These coefficients are to be found in the static EIGEN-GL04S model [20].

The $\mathrm{C}_{20}$ coefficients of the GRGS time series are determined in combining GRACE and LAGEOS-1/2 data. These $\mathrm{C}_{20}$ coefficients are in fact very similar to the ones computed by Cox and Chao [21] (updated version, personal communication).

In the gravity field determination process, a number of time-variable effects have been taken into account: Earth and ocean tides, ECMWF 3-D atmospheric pressure fields, and the MOG2D barotropic ocean model [22]. Since we are interested in the total ocean mass signal, we restore the MOG-2D short-term mass variations removed during the GRACE data processing. More details on the data processing and the GRGS-EIGEN-GL04 geoid solutions, including the associated errors assessment can be found in reference [20].

GRACE gravity field solutions do not include degree-1 spherical harmonic coefficients; neither do the atmospheric and oceanic correction fields. As a consequence, when we add back the ocean model to the solutions, we delete the corresponding degree-1 components. 
These degree-1 terms represent the position of the Earth's center of mass in a terrestrial reference frame. To be consistent with the reference frame used for the Jason-1 altimetry data, the degree-1 coefficients, which are estimated from the seasonal variations of the Earth's center of mass proposed by Chen et al. [23] using satellite laser ranging (SLR) data, are added to the geoid solutions. Note that the secular rate of the geocenter motion is completely unknown at present. There is even no consensus in either its sign or magnitude. In this study we assume that the geocenter rate has negligible impact on global mean sea level trend estimate.

\section{GFZ GRACE gravity field solutions}

We also analyze the publicly available 35 GFZ GRACE gravity field solutions (RL03, called EIGEN-GRACE04S) for the period February 2003 through February 2006 (June 2003 is missing). These geoid solutions consist of spherical harmonics coefficients up to degree and order 120 at monthly intervals and are the result of the latest reprocessing at GFZ using updated processing standards and background models (e.g., applying an ocean pole tide model [24] or using the baroclinic OMCT ocean model for correcting short-term oceanic mass variations, [25]). As a consequence, the $\mathrm{C}_{20}$ coefficient time series is now reliable when compared to Lageos-derived values. Further details such as the processing standards or release notes can be found at the GRACE archives at GFZ ISDC or JPL PO.DAAC.

As for the GRGS geoids, we also add back the monthly mean of the short-term mass variations of the ocean model which were removed during the GRACE data processing and added the degree-1 coefficients estimated from [23].

\section{Main differences between GRGS and GFZ GRACE gravity field solutions}

The gravity field solutions calculated at GRGS and GFZ are the result of a long cooperation already started many years ago. During this collaboration regular software comparisons were made and the background force models and standards were harmonized. As a result, both centres calculated the pre-CHAMP gravity fields GRIM-5S and GRIM-5C and started to generate "European Improved Gravity model of the Earth by New techniques (EIGEN)" for CHAMP and GRACE. One of the latest results is EIGEN-GL04C, a combination of the above described GRGS and GFZ satellite-only models with terrestrial gravity data which was just recently chosen for Jason data reprocessing (http://www.gfzpotsdam.de/pb1/op/grace/results). 
The main differences between the two gravity field time series are : a) the maximum degree of the solutions resulting from the different processing periods and temporal resolution (degree 50 / 10days for GRGS and degree 120 / 30 days for GFZ), b) the different models used to correct short-term oceanic mass variations (barotropic MOG-2D model assuming constant ocean mass for GRGS, baroclinic OMCT model allowing oceanic mass variations for GFZ), and c) the different handling of GRACE instrumental data (GFZ uses the data as provided by JPL while GRGS applies an additional smoothing to the K-band inter-satellite data).

\section{Jason-1 sea level data.}

In this study, we use Topex/Poseidon and Jason-1 altimetry-derived global mean sea level data computed by CLS (Collecte Localisation Satellite, Toulouse). This group provides global mean sea level time series based on Topex-Poseidon (T/P) for January 1993 to April 2002, and on Jason-1 for April 2002 to August 2006, giving 13.5 years of continuous data set. CLS uses the T/P MGDRs (Merged Geophysical Data Records) for Topex/Poseidon and the Jason1 GDRs (Geophysical Data Records) distributed by AVISO. Usual geophysical and atmospheric corrections (tides, wet and dry tropospheric corrections, ionospheric correction, sea state bias as well as instrumental drifts and bias) are applied. Because of abnormal changes observed on the Jason-1 Microwave Radiometer (JMR), the wet tropospheric correction on Jason-1 GDRs has been changed by the ECMWF model. A global bias of 10.4 $\mathrm{cm}$ is removed to align Jason-1 and T/P mean sea level measurements. T/P and Jason- 1 sea level data are first gridded in $2^{\circ} \times 2^{\circ}$ boxes, and then spatially averaged between latitudes $60^{\circ} \mathrm{S}$ and $60^{\circ} \mathrm{N}$ at 10 -days interval, using equi-area weighting. For more details on the corrections applied to compute mean sea level, please refer to the annual report published each year on the

AVISO website: http://www.jason.oceanobs.com/documents/calval/validation_report/j1/annual_report_j1_200 5.pdf.

Note that no inverse barometer (IB) correction is applied to the altimetry-based sea level data, to be consistent with GRACE data that observe the real water mass signal (not IB corrected). Glacial isostatic adjustment (GIA) causes a secular increase in the volume of the ocean basins, which reduces global mean sea level by approximately $-0.3 \mathrm{~mm} /$ year [26]. Thus, in order to explain the T/P and Jason-1-based sea level rise in terms of climate factors, a linear -0.3 
$\mathrm{mm} /$ year correction was subtracted to the global mean sea level time series to account for GIA. Uncertainty on 10-day individual mean sea level values is of the order of $4 \mathrm{~mm}$ [27].

\section{Ocean mass sea level variations}

\section{1 results}

Figure 1 compares the mass component of the global mean sea level variations over the $60^{\circ} \mathrm{S}$ $60^{\circ} \mathrm{N}$ ocean domain, estimated with the two sets of GRACE geoids. A $+1.7 \mathrm{~mm} /$ year correction was applied to both time series to account for GIA, as suggested by Tamisiea et al. [28], using the ICE-5G model [26]. In effect, GIA causes a change in the mean ocean geoid that has to be taken into account for estimating real ocean mass sea level variations. Note that this GIA correction is different from the one applied to altimetry data, because the GIA effects seen by both satellites are different (altimetry: geometric change of ocean basins, GRACE: gravity change over the oceanic domain). The uncertainty associated to this GIA correction is estimated by Tamisiea et al. [28] to $\pm 0.2 \mathrm{~mm} / \mathrm{year}$, depending on the mantle viscosity used in the model.

The agreement between the GRGS- and GFZ-derived ocean mass time series appears extremely good reflecting the very similar GRACE data processing strategy, applied background models and harmonized processing standards and software.

The least-squares fitted annual amplitudes and phases of the two time series are presented in Table 1. The GRGS-derived ocean mass sea level curve has an annual amplitude of $7.5 \mathrm{~mm}$ and a phase of $285.6^{\circ}$ (maximum on October 17 ) while the GFZ-derived ocean mass sea level curve has an annual amplitude of $7.1 \mathrm{~mm}$ and a phase of $279.8^{\circ}$ (maximum on October 11).

Figure 2 shows the residual mass component of global mean sea level variations after removal of the annual and semi-annual cycles in both time series. Interannual fluctuations exhibited by the two curves agree rather well. Both residual time series show a positive trend from the beginning of 2003. The GRGS-derived ocean mass sea level trend $(+1.3 \pm 0.2 \mathrm{~mm} / \mathrm{year})$ and the GFZ-derived estimate $(+1.1 \pm 0.4 \mathrm{~mm} /$ year $)$ are of the same order of magnitude. These rates are also presented in Table 2. From these two values, we estimate the mean trend of the ocean mass component to be $1.2 \pm 0.5 \mathrm{~mm} /$ year over the last 3.5 years, the error bar taking into 
account the dispersion around the mean, formal errors and GIA correction uncertainty. Note that formal errors on ocean mass sea level trend estimates are still quite large, because of the short time period of GRACE observations. In the future, longer GRACE time series will help reducing errors bars on long-term trend estimates.

\subsection{Discussion}

During the past decade, several studies have estimated the terrestrial water contribution to the annual mean sea level using global land surface models outputs [29-33]. The general approach of these studies was to estimate the annual ocean mass component from the satellite altimetry-based global mean sea level, after correcting the latter for the steric component (essentially thermal expansion) and taking into account the small annual variation of atmospheric water vapour, and then to compare the ocean mass component to terrestrial water storage based on global land surface models. The annual cycle of global mean sea level has an amplitude of approximately $5 \mathrm{~mm}$, with a maximum in October. Because the annual cycle of the steric sea level also has an amplitude of about $5 \mathrm{~mm}$, but is in phase opposition, once corrected for steric effects (using climatologies in general), the residual annual mean sea level has an amplitude of 8-10 mm, with a maximum in September.

The annual ocean mass variation reported in the present study is consistent with this range. It is also in good agreement with recent estimates based on GRACE [6, 15]. Chambers et al. [15] used the very first release of CSR-derived GRACE data, over the short period of August 2002 to December 2003, to estimate the annual cycle of global $\left( \pm 66^{\circ}\right)$ mean ocean mass and found an amplitude of $9.4 \mathrm{~mm}$, with a maximum in mid-October. Although our estimate agrees well with [15] in terms of phase, our amplitude (around $7.3 \mathrm{~mm}$ ) is smaller. This difference can be due to the different time span, different and improved GRACE instrumental and geoid data processing, different treatment of low degree harmonic coefficients (especially the degree 2, order 0 term) and treatment of the ocean pole tide. Recently Chen et al. [6] estimated seasonal global mean sea level changes using different data sources, including satellite altimetry data, in situ hydrographic data, land water storage from the GLDAS (Global Land Data Assimilation System) land surface model, atmospheric data from NCEP (National Centers for Environmental Prediction), and GRACE data. They compared the different estimates and found very good agreement between GRACE and other data in a number of cases. Finally, they provided a best estimate of the ocean mass annual cycle, with an 
amplitude of $7.2 \mathrm{~mm}$, maximum in early-October (around October 8). These values are in very good agreement with our estimate.

In principle, the trends reported in Table 2 represent the ocean mass increase due to change in land water storage and land ice melt. For the latter, most recent estimates indicate that mountain glaciers melting has contributed to $0.8+/-0.4 \mathrm{~mm} /$ year over the last decade [34]. Recently, estimates of the mass balance of Greenland and Antarctica ice sheets based on remote sensing have been proposed for the last decade [11-14, 35-42]. These results suggest that on average, Greenland is loosing ice mass, the process accelerating in recent years. The Antarctic ice sheet is in a state of slight negative imbalance. Although much uncertainty exists for both ice sheets due to incomplete coverage in space and time, we conclude that the Greenland ice sheet could have contributed to about $0.3 \pm 0.15 \mathrm{~mm} /$ year to recent years sea level rise and that the Antarctica ice sheet may be close to balance (although probable slight mass loss may prevail).

Summing the different land ice melt contributions, we find a value of approximately 1.1 $\mathrm{mm} /$ year equivalent sea level rise over the recent years. The GRACE-based ocean mass increase computed in the present paper, of $1.2 \pm 0.5 \mathrm{~mm} /$ year, is compatible with this value considering the large error bars. However, it represents the total land water contribution, i.e., land ice plus land waters. The latter is very poorly known and is up to now estimated from land surface models only [32,33]. A recent study based on GRACE [43] suggests that over the past 3 years the land water component is $0.25 \pm 0.05 \mathrm{~mm} /$ year. This would increase the total ocean mass component up to about $1.35 \mathrm{~mm} /$ year, in good agreement with our ocean mass change estimate $(1.2 \pm 0.5 \mathrm{~mm} /$ year$)$.

\section{Steric sea level variations}

Steric sea level variations, averaged over the $60^{\circ} \mathrm{S}-60^{\circ} \mathrm{N}$ ocean domain, are determined from combined Jason-1 and GRACE-derived sea level time series, at 10-day interval, from August 2002 to April 2006 for the GRGS-geoids, and at monthly interval from February 2003 to February 2006 for the GFZ-geoids. Note that this method provides an estimate of the total steric (thermosteric plus halosteric, for the entire water column) sea level variations, but in terms of global mean, the halosteric is negligible [44].

Figure 3 shows the two 'Jason-1 minus GRACE' steric sea level time series. The agreement between GRGS-derived and GFZ-derived steric sea level curves is good. 
The least-squares fitted annual amplitudes and phases of the two time series are presented in Table 1. The 'Jason-1 minus GRGS'-derived steric sea level curve has an amplitude of 5.6 $\mathrm{mm}$ and a phase of $69.3^{\circ}$ (maximum on March 11) while the 'Jason-1 minus GFZ'-derived steric sea level curve has an amplitude of $6.1 \mathrm{~mm}$ and a phase of $68.7^{\circ}$ (maximum on March 11).

We compare the above 'Jason-1 minus GRACE' estimates of steric sea level variations with the thermosteric sea level curve computed using the WOD-04 climatology [45] and Ishii et al. [46] ocean temperature data. The results are shown in Fig. 4. We note satisfactory agreement between 'Jason-1 minus GRACE' and in situ-based thermal expansion for the annual cycle, although the latter presents smaller amplitudes, especially with Ishii et al. [46] data. Annual amplitudes and phases of each curve are also presented in Table 1. Note that Garcia et al. [16], using geoid data from the Center for Space Research (GRACE project) found an amplitude of $6.4 \mathrm{~mm}$ and a $72.7^{\circ}$ phase, very similar to our 'Jason-1 minus GFZ' estimate.

We further compute interannual steric sea level for both 'Jason-1 minus GRACE' data sets (after removal of annual and semi-annual cycles). These are shown in Fig.5, superimposed to the Ishii et al. [46] steric sea level curve (annual and semi-annual cycles removed). The two 'Jason-1 minus GRACE' curves present similar behaviour, with an increasing trend during the 3.5-year period, also seen in the Ishii et al. [46] thermal expansion curve up to mid-2003, but not beyond. The 'Jason-1 minus GRGS'-derived steric sea level curve presents a $+1.9 \pm$ $0.2 \mathrm{~mm} /$ year rate of rise between August 2002 and April 2006, which exactly corresponds to the thermal expansion trend computed from Ishii et al. [46] data, between 1998 and mid-2003 $(+1.9 \pm 0.1 \mathrm{~mm} /$ year $)$. Over the longer 1993-2003 period, the thermal expansion slope derived from in situ data is smaller, about $1.5 \pm 0.3 \mathrm{~mm} /$ year depending on the dataset used [47], but still of the same order of magnitude. The 'Jason-1 minus GFZ'-derived steric sea level trend is even higher, $+2.9 \pm 0.4 \mathrm{~mm} / \mathrm{year}$, but this is due to the shorter time span of the data (February 2003- February 2006). Over this short time span, the Jason-1 sea level curve rises by $4.0 \pm 0.4 \mathrm{~mm} /$ year, instead of $+3.1 \pm 0.2 \mathrm{~mm} /$ year for the April 2002- April 2006 period. This above result is in contrast to the strong decreasing trend of thermal expansion over mid-20032005, as suggested by in situ ocean temperature data (e.g., Ishii et al., [46]): during the common period [August 2002-December 2005], thermal expansion falls at a rhythm of $2.8 \pm 0.2 \mathrm{~mm} /$ year. This negative trend in thermal expansion has been also reported in recent 
other studies (e.g., Lyman et al. [48], S. Levitus, personal communication, 2006). Such a global ocean cooling, if real, would suggest a sudden dramatic increase in the gain of ocean mass (to a rate of about $6.6 \mathrm{~mm} / \mathrm{year}$ ), as Jason-1 observations show a continuing sea level rise during this recent 2003-2005 period (at a rate of 3.8 $\pm 0.4 \mathrm{~mm} /$ year) - see Fig.6 for a summary. Recent ice mass loss from the ice sheets does not support such an observation (e.g., [49]). In addition, we do not observe such a high rate in ocean mass gain from GRACE data. As the present study is restricted to the $60^{\circ} \mathrm{S}-60^{\circ} \mathrm{N}$ oceanic domain, we check that high latitude oceans are not responsible for such a large mass gain. We have computed the global $\left(90^{\circ} \mathrm{S}-90^{\circ} \mathrm{N}\right)$ ocean mass variations using GRACE data (as done in section 3.1 for $60^{\circ} \mathrm{S}-$ $60^{\circ} \mathrm{N}$ ). The GRGS-derived and GFZ-derived global ocean mass sea level trends (of $+0.8 \pm 0.1$ $\mathrm{mm} /$ year and $+0.85 \pm 0.2 \mathrm{~mm} /$ year respectively) are smaller than the $60^{\circ} \mathrm{S}-60^{\circ} \mathrm{N}$ estimate $(1.2 \pm 0.5 \mathrm{~mm} /$ year). Thus high latitude ocean mass variations can not explain the high rate in ocean mass gain implied by the negative trend in thermal expansion deduced from in situ data.

The reason for the discrepancy between our 'Jason-1 minus GRACE'-derived steric sea level trend, and the in situ data-based thermosteric sea level trend for the years 2003-2005, is unclear and needs further investigation. We suspect that in situ-based estimates could be biased due to the recent introduction of new ARGO floats data into ocean temperature analysis. Data sampling issues, or even instrumental correction problems, are to be investigated to quantify the impact of ARGO data on recent steric sea level estimates.

\section{Conclusion.}

We have estimated the two main components of the global mean sea level rise for the recent years, i.e. ocean mass change and thermal expansion, by combining the observations of two complementary satellites: GRACE and Jason-1.

Using two different releases of GRACE data (GRGS-EIGEN-GL04 and GFZ EIGENGRACE04S geoids), we first estimate the ocean mass component of global mean sea level variations, averaged over $60^{\circ} \mathrm{S}-60^{\circ} \mathrm{N}$, between August 2002 and April 2006. In terms of annual variations, we find a good agreement with previous studies, both in amplitude $(7.3 \pm 0.2$ $\mathrm{mm}$ equivalent sea level) and phase (maximum on October $14 \pm 3$ ). Once this seasonal cycle is removed, we observe a general positive trend of ocean mass sea level $(1.2 \pm 0.5 \mathrm{~mm} /$ year $)$, 
which is consistent with independent observations of land ice and land water changes (about $+1.35 \mathrm{~mm} /$ year).

We also present an estimate of the steric mean sea level variations, for the period August 2002 to April 2006, by computing the Jason-1 total sea level minus GRACE ocean mass sea level. We find satisfactory agreement between our estimate of the annual steric sea level and the one deduced from in situ ocean temperature data, even if the latter presents smaller amplitude, of about $1-2 \mathrm{~mm}$.

When we focus on interannual steric sea level variations, we find a positive trend in the steric sea level of $1.9 \pm 0.2 \mathrm{~mm} /$ year between August 2002 and April 2006, which is consistent with the observed trend deduced from in situ ocean temperature data over the period 1993-2003. However, in situ-based steric sea level shows a dramatic downward trend beyond this date, in complete disagreement with our estimate based on altimetry and GRACE data over the same period. Further investigation is needed to solve this problem.

However, the uncertainty on trend estimates is still large. In the future, longer and improved GRACE time series will help reducing these errors bars.

\section{Acknowledgements.}

We thank Michael Ablain from CLS (Collecte Localisation Satellite), Toulouse, for having provided the Topex-Poseidon and Jason-1-based global mean sea level time series. We are also grateful to the two anonymous reviewers for helpful comments. One of us (AL) benefited from a CNES post-doc grant. 


\section{References.}

[1] Tapley, B.D., S. Bettadpur, M. Watkins and C. Reigber, The Gravity Recovery and Climate Experiment : Mission overview and Early results, Geophys. Res. Lett., 31, L09607 (2004a) doi:10.1029/2004GL019920.

[2] Tapley, B.D., S. Bettadpur, J.C. Ries, P.F. Thompson and M. Watkins, GRACE measurements of mass variability in the Earth system, Science, 305 (2004b) 503-505.

[3] Wahr, J., S. Swenson, V. Zlotnicki and I. Velicogna, Time-variable gravity from GRACE: first results, Geophys. Res. Lett., 31 (2004) L11501, doi:10.1029/2004GL019779.

[4] Rodell, M. and J.S. Famiglietti, Detectability of variations in continental water storage from satellite observations of the time dependent gravity field, Water Resour. Res., 35 (9) (1999), 2705-2723.

[5] Chen, J.L., C.R. Wilson, B.D. Tapley and J. Ries, Low degree gravitational changes from GRACE: validation and interpretation, Geophys. Res. Lett., 31(22) (2004) L22607, doi:10.1029/2004GL021670.

[6] Chen, J.L., C.R. Wilson, B.D. Tapley, J.S. Famiglietti and M. Rodell, Seasonnal global mean sea level change from satellite altimeter, GRACE, and geophysical models, J. Geod., (2005) doi 10.1007/s00190-005-0005-9.

[7] Ramillien, G., F. Frappart and A. Cazenave, Change in land water storage from 2 years of GRACE satellite data, Earth and Planetary Science Letters, 235 (2005) 283-301.

[8] Seo, K-W., C. R. Wilson, J. S. Famiglietti, J. Chen and M. Rodell, Terrestrial Water Mass Load Changes from GRACE, Wat. Resour. Res., in press (2006).

[9] Schmidt, R., F. Flechtner, Ch. Reigber, P. Schwintzer, A. Günter, P. Doll, G. Ramillien, A. Cazenave, S. Petrovic, H. Jochman and J. Wunsch, GRACE observations of changes in continental water storage, Global and Planetary Change, Vol 50/1-2 (2006) 112-126, doi: 10.1016/j.gloplacha.2004.11.018.

[10] Swenson, S. C., and P. C. D. Milly, Climate model biases in seasonality of continental water storage revealed by satellite gravimetry. Water Resources Research, 42, W03201 (2006), doi:10.1029/2005WR004628.

[11] Velicogna, I., and J. Wahr, Greenland mass balance from GRACE, Geophys. Res. Lett., 32, (2005) L18505, doi:10.1029/2005GL023955.

[12] Velicogna, I., and J. Wahr, Measurements of time-variable gravity show mass loss in Antarctica, Sciencexpress, (2006) 10.1126/science.1123785. 
[13] Ramillien, G., A. Lombard, A. Cazenave, E. R. Ivins, M. Llubes, F. Remy and R. Biancale, Interannual variations of the mass balance of the Antarctica and Greenland ice sheets from GRACE, Global and Planetary Change, in press (2006).

[14] Chen, J.L., C.R. Wilson and B.D. Tapley, Satellite gravity measurements confirm accelerated melting of the Greenland ice sheet, Science, 313 (2006), 1958.

[15] Chambers, D.P., J. Wahr and R. S. Nerem, Preliminary observations of global ocean mass variations with GRACE, Geophys. Res. Lett., Vol. 31, L13310 (2004).

[16] Garcia, D., G. Ramillien, A. Lombard and A. Cazenave, Steric sea level variations inferred from combined Topex/Poseidon altimetry and GRACE gravimetry, Pageoph, in press (2006).

[17] Chambers, D.P., Observing seasonal steric sea level variations with GRACE and satellite altimetry, J.Geophys. Res., 111 (C3) (2006) C03010, 10.1029/2005JC002914.

[18] Wahr, J., M. Moleenar and F. Bryan, Time variability of the Earth's gravity field: Hydrological and oceanic effects and their possible detection using GRACE, J. Geophys. Res., 103, B12 (1998) 30205-30229.

[19] Swenson, S. and J. Wahr, Methods for inferring regional surface-mass anomalies from Gravity Recovery and Climate Experiment (GRACE) measurements of time-variable gravity, J. Geophys. Res., 107, B9, (2002) 2193, doi:10.1029/2001JB000576.

[20] Biancale, R., J.-M. Lemoine, G. Balmino, S. Loyer, S. Bruisma, F. Perosanz, J.-C. Marty and P. Gégout, "3 years of geoid variations from GRACE and LAGEOS data at 10-day intervals from July 2002 to March 2005”, CNES/GRGS product, data available on CD-ROM, also on BGI web page: http://bgi.cnes.fr/ (2006).

[21] Cox, C., and B.F. Chao, Detection of a large-scale mass redistribution in the terrestrial system since 1998, Science, 297 (2002).

[22] Carrere, L. and F. Lyard, Modeling the barotropic response of the global ocean to atmospheric wind and pressure forcing - Comparisons with observations, Geophys. Res. Let., $30,6,(2003) 1275$.

[23] Chen, J.L., C.R. Wilson, R.J. Eanes and R.S. Nerem, Geophysical interpretation of the observed geocenter variations, J. Geophys. Res., 104, B2 (1999) 2683-2690.

[24] Desai, S.D., Observing the pole tide with satellite altimetry, J. Geophys. Res., 107, C11 (2002) 3186 .

[25] Flechtner, F., GRACE AOD1B Product Description Document, online available from http://isdc.gfz-potsdam.de/grace (2005). 
[26] Peltier, W.R., Global glacial isostasy and the surface of the ice-age Earth : the ICE-5G (VM2) model and GRACE, Annual Rev. Earth Planet Sci, 32 (2004) 111-149.

[27] Nerem, R.S., and G.T. Mitchum, Sea Level Change, in Satellite altimetry and Earth sciences, Fu and Cazenave, Ed., Academic Press, San Diego (2001).

[28] Tamisiea, M.E., J.X. Mitrovica, R.S. Nerem, E.W. Leuliette, and G.A. Milne, Correcting satellite derived estimates of global mean sea level change for glacial isostatic adjustment, Geophys. J. Int., in press (2006).

[29] Chen, J.L., C.R. Wilson, D.P. Chambers, R.S. Nerem and B.D. Tapley, Seasonal global water mass budget and mean sea level variations, Geophys. Res. Lett., 32, 19 (1998) 35553558 .

[30] Minster, J.F., A. Cazenave, Y.V. Serafini, F. Mercier, M.C. Gennero and P. Rogel, Annual cycle in mean sea level from Topex-Poseidon and ERS-1: inference on the global hydrological cycle, Global and Planetary Change, 20 (1999) 57-66.

[31] Cazenave, A., F. Remy, K. Dominh and H. Douville, Global ocean mass variations, continental hydrology and the mass balance of Antarctica ice sheet at seasonal timescale, Geophys. Res. Lett., Vol. 27, No. 22, (2000) 3755-3758.

[32] Milly, P.C.D., A. Cazenave, and M.C. Gennero, Contribution of climate-driven change in continental water storage to recent sea-level rise, Proc. Natl. Acad. Sci. U. S. A., 100, 13 (2003) 158-13,161.

[33] Ngo-Duc T., K. Laval, Y. Polcher and A. Cazenave, Analyses of the contribution of continental water to sea level variations during the 1997-1998 ENSO event; Comparison between the AMIP simulations and the Topex/Poseidon satellite data., J. Geophys. Res., 110 (2005) D09103, doi:10.1029/2004JDO04940.

[34] Dyurgerov, M., and M.F. Meier, Glaciers and Changing Earth System: a 2004 snapshot, INSTAAR, Boulder (2005).

[35] Krabill, W., E. Hanna, P. Huybrechts, W. Abdalati, J. Cappelen, B. Csatho, E. Frederick, S. Manizade, C. Martin, J. Sonntag, R. Swift, R. Thomas, and J. Yungel, Greenland Ice Sheet: Increased coastal thinning, Geophys. Res. Lett. , 31, (2005) L24402, doi:10.1029/2004GL021533.

[36] Thomas, R.H., Greenland : recent mass balance observations, in Mass balance of the cryosphere, Observations and modelling of contemporary and future changes, ed. J.L. Bamber and A.J. Payne, Cambridge University Press, Cambridge (2004).

[37] Johannessen, O.M., K. Khvorostovsky, M.W. Miles and L.P. Bobylev, Recent ice sheet growth in the interior of Greenland, Science, 310 (2005) 1013-1016. 
[38] Zwally, H.J., M.B. Giovinetto, J. Li, H.G. Cornejo, M.A. Beckley, A.C. Brenner, J.L. Saba and D. Yi, Mass changes of the Greenland and Antarctica ice sheets and shelves and contributions to sea level rise: 1992-2002, J. Glaciology, 51 (2005) 509-524.

[39] Rignot, E., and P. Kanagaratnam, Changes in the velocity structure of the Greenland ice sheet, Science, 311 (2006) 986-990.

[40] Rignot, E., and R. Thomas, Mass balance of polar ice sheets, Science, 297 (2002) 15021506.

[41] Davis, C.H., Y. Li, J.R. McDonnell, M.M. Frey and E. Hanna, Snowfall-driven growth in East Antarctica ice sheet mitigates recent sea level rise, Science, 308 (2005) 1898-1907.

[42] Luthcke, S.B., H.J. Zwally, W. Abdalati, D.D. Rowlands, R.D. Ray, R.S. Nerem, F.G. Lemoine, J.J. McCarthy, and D.S. Chinn, Recent Greenland ice mass loss by drainage system from satellite gravimetry observations, Sciencexpress, (2006) 10.1126/science.1130776.

[43] Bouhours, S., G. Ramillien, A. Lombard, A. Cazenave, F. Flechtner and R. Schmidt, Land water contribution to sea level from GRACE, Geophys. J. Int., submitted (2006).

[44] Antonov, J.I., S. Levitus, and T.P. Boyer, Steric sea level variations during 1957-1994: Importance of salinity. Journal of Geophysical Research, 107 (C12), (2002) 8013, doi:10.1029/2001JC000964.

[45] Levitus, S., J. Antonov, and T. Boyer, Warming of the world ocean, 1955-2003, Geophys. Res. Lett., 32 (2005) L02604.

[46] Ishii, M., M. Kimoto, K. Sakamoto, and S.I. Iwasaki, Steric sea level changes estimated from historical ocean subsurface temperature and salinity analyses, Journal of Oceanography, 62 (2) (2006) 155-170.

[47] Lombard, A., A. Cazenave, P.Y. Le Traon, S. Guinehut and C. Cabanes, Perspectives on present-day sea level change: a tribute to Christian Le Provost, Ocean Dynamics, published online, doi:10.1007/s10236-005-0046-x (2006).

[48] Lyman, J.M., J.K. Willis, and G.C. Johnson, Recent cooling of the upper ocean, Geophys. Res. Lett., Vol. 33, No. 18 (2006), L18604.

[49] Cazenave, A., How fast are the ice sheets loosing mass, Sciencexpress, (2006) 10.1126/science.1133325. 


\begin{tabular}{|l|c|c|}
\hline & $\begin{array}{c}\text { Annual } \\
\text { Amplitude } \\
(\mathrm{mm})\end{array}$ & $\begin{array}{c}\text { Annual } \\
\text { Phase }\left(^{\circ}\right)\end{array}$ \\
\hline $\begin{array}{l}\text { GRGS Ocean mass }\left( \pm 60^{\circ}\right) \\
\text { August 2002 - April } 2006\end{array}$ & 7.5 & 285.6 \\
\hline $\begin{array}{l}\text { GFZ Ocean mass }\left( \pm 60^{\circ}\right) \\
\text { February } 2003 \text { - February } 2006\end{array}$ & 5.6 & 279.8 \\
\hline $\begin{array}{l}\text { 'Jason-1 minus GRGS' steric component }\left( \pm 60^{\circ}\right) \\
\text { August } 2002 \text { - April } 2006\end{array}$ & 6.1 & 69.3 \\
\hline $\begin{array}{l}\text { 'Jason-1 minus GFZ steric component }\left( \pm 60^{\circ}\right) \\
\text { Thermal expansion from WOD-04 Climatology }\left( \pm 60^{\circ}\right)\end{array}$ & 5.1 & 84.6 \\
\hline $\begin{array}{l}\text { Thermal expansion from Ishii et al. }[46] \text { data }\left( \pm 60^{\circ}\right) \\
\text { June 2002 - December } 2005\end{array}$ & 4.0 & 89.6 \\
\hline
\end{tabular}

Table 1. Annual amplitudes and phases of the best fitting sinusoids to the time series shown in

Fig.1, 3 and 4. Adjustments are defined over the periods indicated in bold characters. 


\begin{tabular}{|l|c|}
\hline & Trend (mm/year) \\
\hline $\begin{array}{l}\text { GRGS Ocean mass }\left( \pm 60^{\circ}\right) \\
\text { August } 2002-\text { April } 2006\end{array}$ & $+1.3 \pm 0.2$ \\
\hline $\begin{array}{l}\text { GFZ Ocean mass }\left( \pm 60^{\circ}\right) \\
\text { February 2003 - February 2006 }\end{array}$ & $+1.1 \pm 0.4$ \\
\hline \begin{tabular}{l} 
Jason-1 $\left( \pm 60^{\circ}\right) \quad$ August 2002 - April 2006 \\
\hline Jason-1 $\left( \pm 60^{\circ}\right)$ February 2003 - February 2006
\end{tabular} & $+3.1 \pm 0.2$ \\
\hline $\begin{array}{l}\text { 'Jason-1 minus GRGS' steric component }\left( \pm 60^{\circ}\right) \\
\text { August 2002 - April 2006 }\end{array}$ & $+4.0 \pm 0.5$ \\
\hline 'Jason-1 minus GFZ' steric component $\left( \pm 60^{\circ}\right)$ & $+1.9 \pm 0.2$ \\
\hline $\begin{array}{l}\text { thermal expansion from Ishii et al. [46] data }\left( \pm 60^{\circ}\right) \\
\text { August 2002 - December 2005 }\end{array}$ & $+2.9 \pm 0.4$ \\
\hline
\end{tabular}

Table 2. Trends of the time series shown in Fig.1, 3 and 4, and of Jason-1 sea level time series, after removal of annual and semi-annual components (see Fig. 2, 5, 6). Adjustments are defined over the periods indicated in bold characters. 


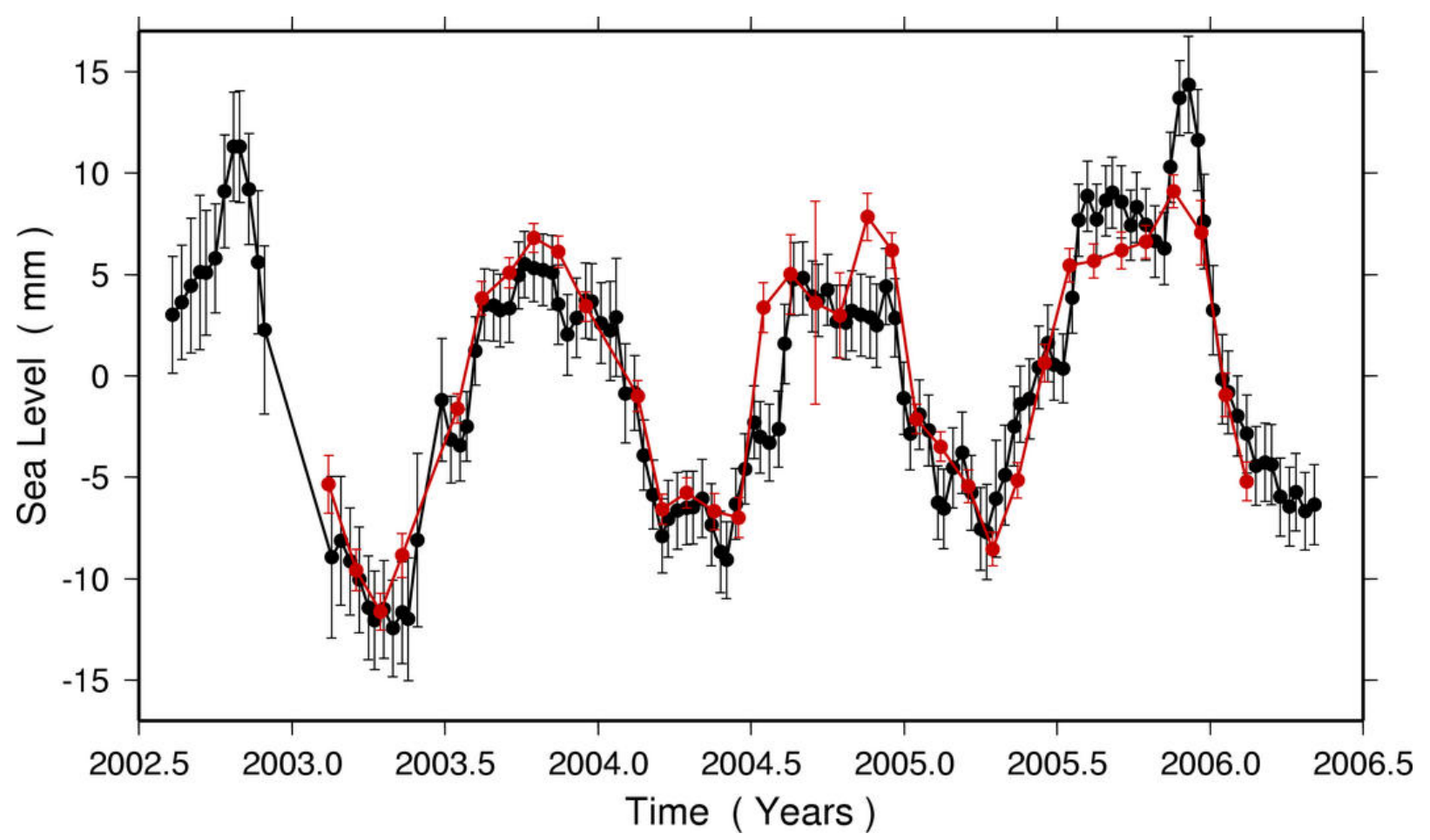

Fig.1. GRACE-derived mass component of sea level variations, computed using GRGS geoid solutions (black curve) at 10-day intervals between August 2002 and April 2006, and GFZ geoids (red curve) at monthly intervals between February 2003 and February 2006. Note that $\mathrm{a}+1.7 \mathrm{~mm} /$ year linear correction was applied to the time series to account for glacial isostatic adjustment (GIA). 


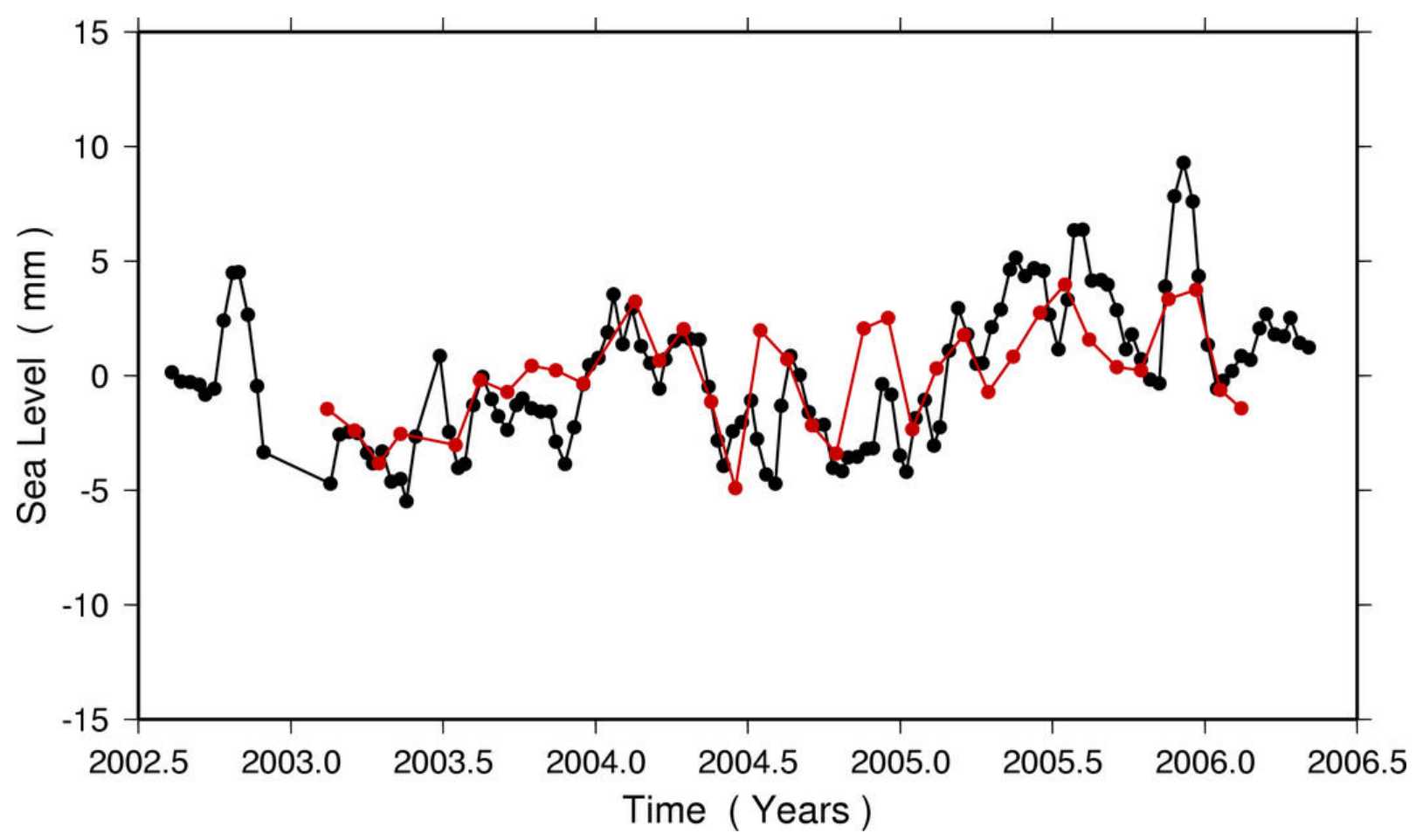

Fig.2. Interannual GRACE-derived mass component of sea level variations, computed using GRGS-geoids (black curve) at 10-day intervals, and GFZ-geoids (red curve) at monthly intervals. Note that annual and semi-annual seasonal cycles have been removed from both time series to emphasize interannual variations. 


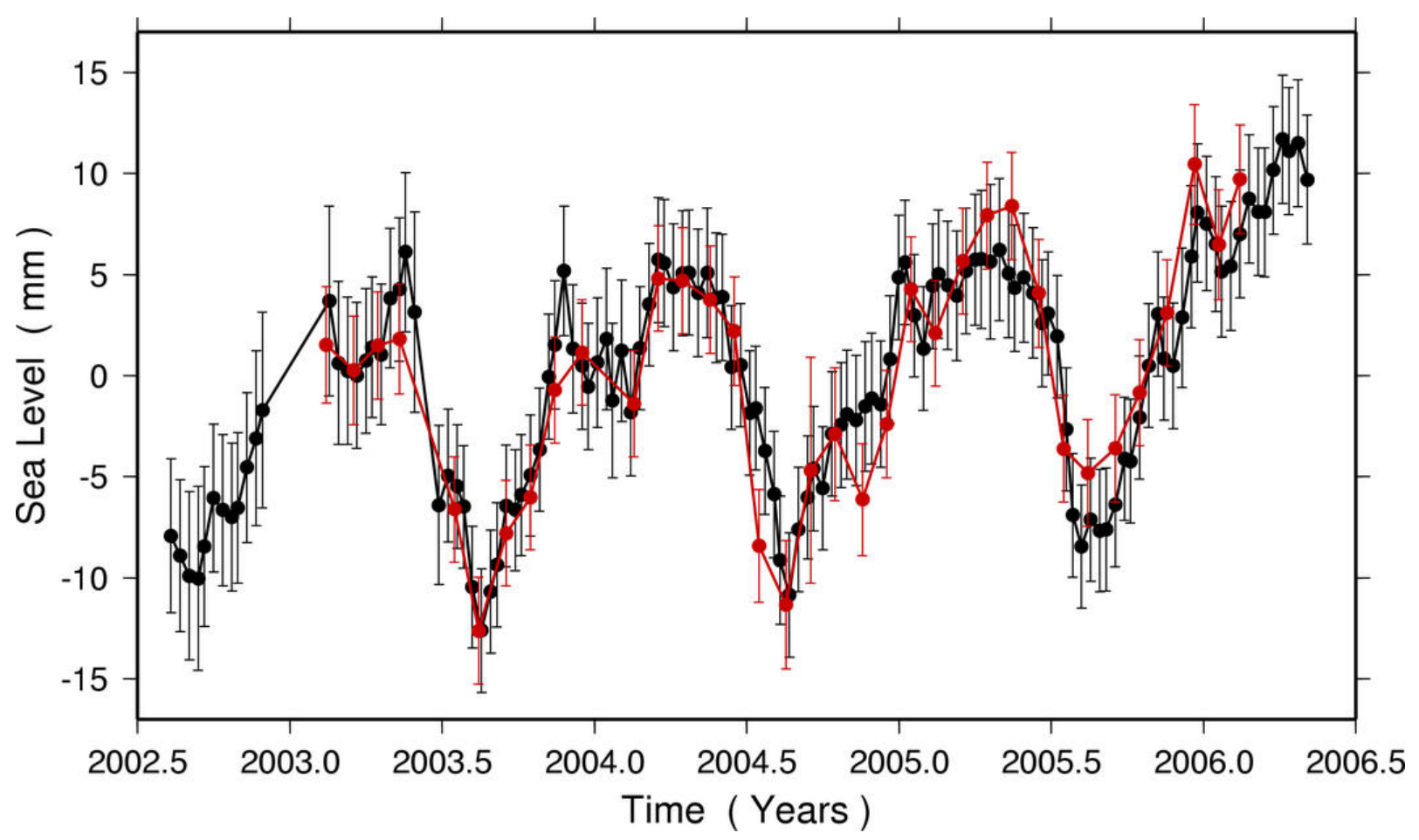

Fig.3. 'Jason-1 minus GRACE'-derived steric sea level variations at 10-day intervals (black curve - GRGS-geoids), and at monthly intervals (red curve - GFZ-geoids). Error bars are estimated by $\sqrt{\left(\Delta E_{\text {Jason-1 }}^{2}+\Delta E_{\text {GRACE }}^{2}\right)}$ with $\Delta E_{\text {Jason-1 }} \approx 2.5 \mathrm{~mm}$ and $\Delta E_{\text {GRACE }}$ computed in this study (shown in Figure 1). 


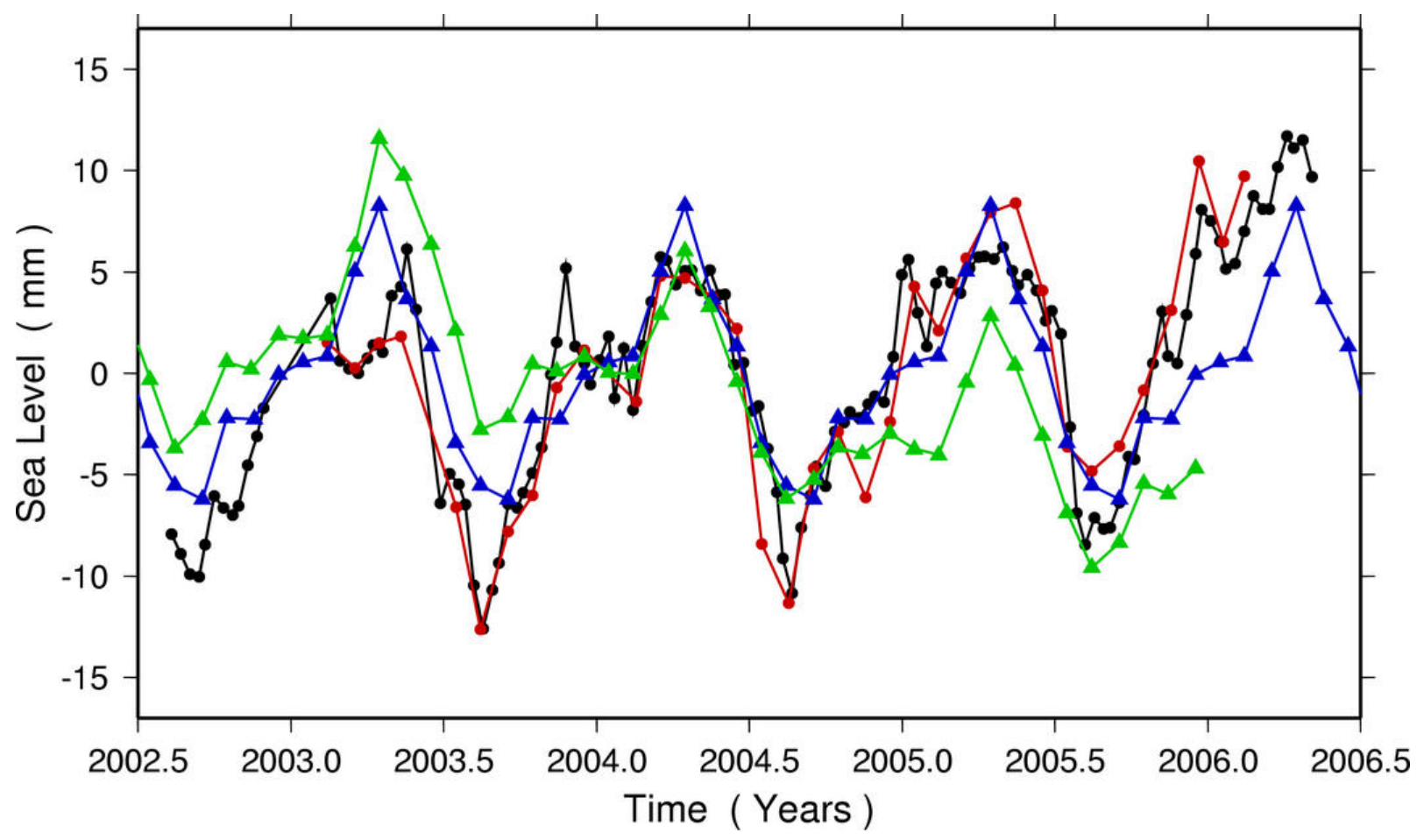

Fig.4. 'Jason-1 minus GRACE'-derived steric sea level variations at 10-day intervals (black curve, GRGS-geoids), and at monthly intervals (red curve, GFZ geoids). Errors bars (not shown here) are the same as in Fig.2 (about 3mm). Climatological WOD-04-derived monthly steric sea level variations (blue curve) and Ishii et al. [46]-derived monthly steric sea level (green curve) are superimposed. Associated error bars are estimated to about $5 \mathrm{~mm}$ for these monthly means. 


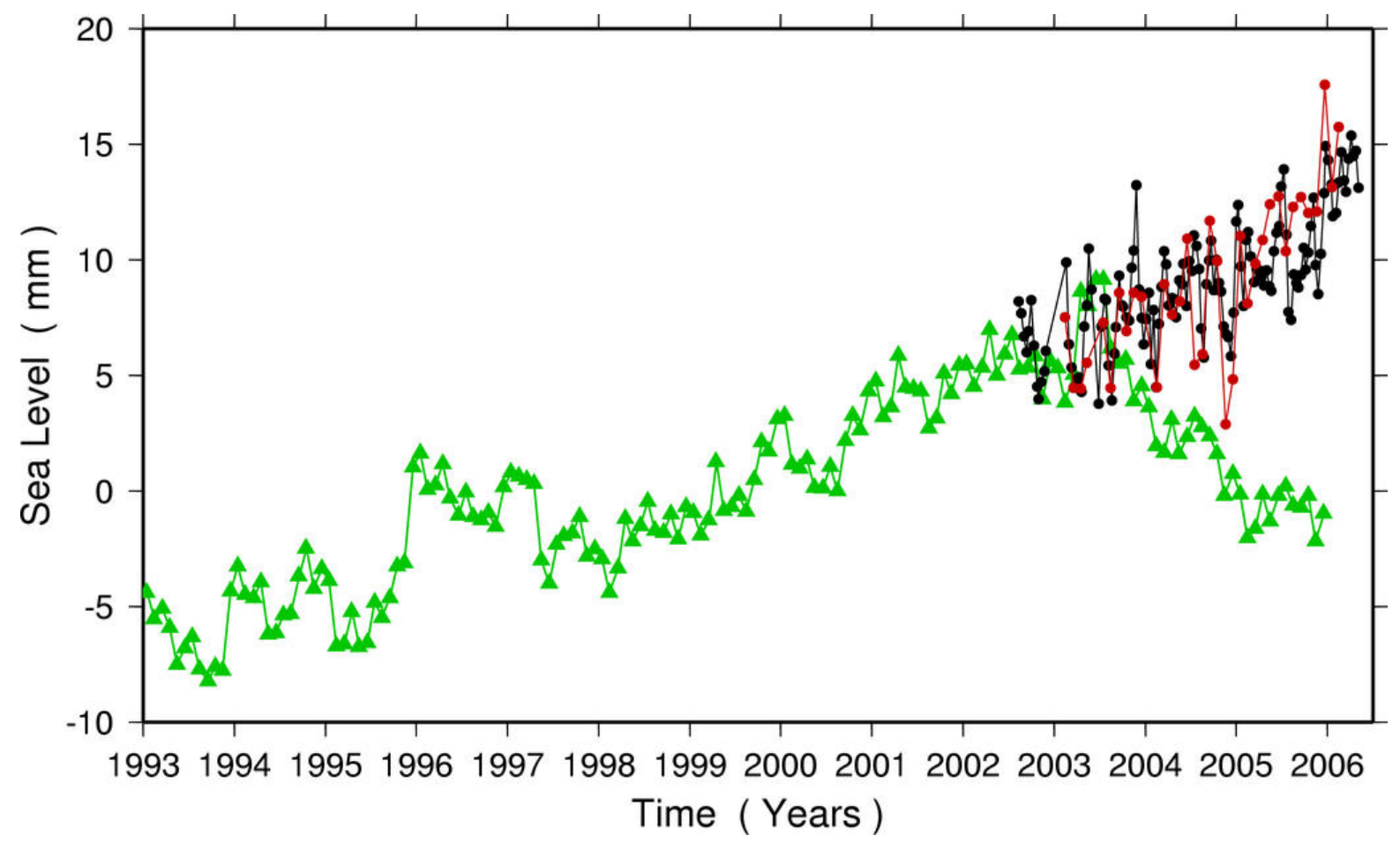

Fig.5. Thermosteric sea level variations computed using Ishii et al. [46] global ocean temperature data down to $700 \mathrm{~m}$ (green curve) from 1993 to 2005, and 'Jason-1 minus GRACE'-derived steric sea level variations (black curve: GRGS geoids, red curve: GFZ geoids). Note that seasonal cycles have been removed from all time series to emphasize interannual variations. 


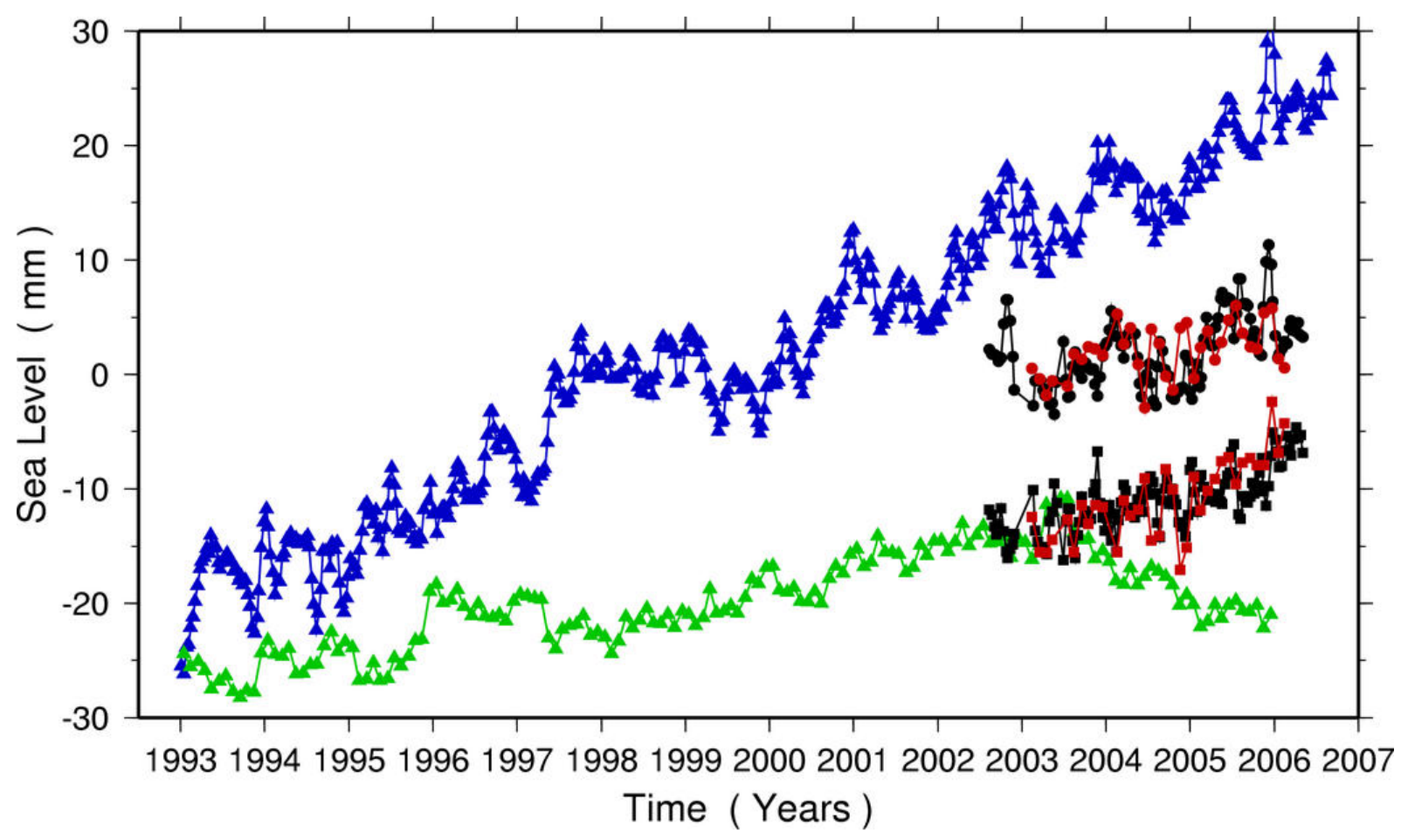

Fig.6. Upper blue curve : T/P and Jason-1 derived interannual sea level variations from 1993 to 2006, middle curves (corresponding to Fig.2) : GRACE-derived ocean mass component of interannual sea level variations (black curve: GRGS geoids, red curve: GFZ geoids), lower curves (corresponding to Fig.5) : thermosteric sea level variations computed using Ishii et al. [46] global ocean temperature data (green curve) from 1993 to 2005, and 'Jason-1 minus GRACE'-derived steric sea level variations (black curve: GRGS geoids, red curve: GFZ geoids). Note that seasonal cycles have been removed from all time series to emphasize interannual variations. 